\title{
INTRODUCCIÓN
}

\section{VIOLENCIA CONTRA LAS MUJERES: LAS DIMENSIONES DE LA DESIGUALDAD}

\author{
Ana Isabel Blanco García
}

Podríamos comenzar la presentación de este monográfico sobre la violencia contra las mujeres haciendo un recuento del número de víctimas que se han producido a lo largo de los años en los que este asunto comenzó a convertirse en parte de la agenda política ${ }^{1}$, o centrándonos en la discusión acerca de la denominación “correcta” de este problema social (desde el punto de vista sociológico, psicológico, jurídico, etc. ${ }^{2}$ ) o elaborando una justificación de la pertinencia del mismo desde criterios democráticos.

Sin embargo, creo interesante hacerlo entrando directamente en el debate que desde hace unos años recorre todo el sustrato del pensamiento feminista y del que en buena medida es deudor el propio título de nuestra revista.

Cuestiones de género: de la igualdad y la diferencia es una publicación que deliberadamente intenta dar cabida a las diferentes maneras de enfocar los estudios de las mujeres que están teniendo lugar dentro de la propia teoría feminista. Me refiero (y no solo, pero sí principalmente) al debate fundamental entre el feminismo de la igualdad

\footnotetext{
${ }^{1}$ El Boletín Estadístico del Observatorio Estatal de Violencia sobre la Mujer, constituido el 29 de junio de 2006 y adscrito al Ministerio de Trabajo y Asuntos Sociales a través de la Delegación Especial del Gobierno contra la Violencia sobre la Mujer, está instituido como órgano colegiado encargado de recabar cuanta información obre en poder de las instituciones, tanto públicas como privadas y que desde el ámbito social, sanitario, educativo, judicial y policial entre otros, están implicados en la lucha contra la violencia de género. En él se puede consultar la incidencia y prevalencia de la violencia de género. Ver www.mtas.es/igualdad/violencia.htm

${ }^{2}$ Ver por ejemplo VV.AA. (2006) II Congreso sobre violencia de género. Madrid, Consejo General del Poder Judicial; y de entre los últimos monográficos al respecto, por su carácter innovador y la solidez de sus contribuciones, MAÑAS VIEJO, C. (coord.) (2005): Violencia estructural y directa: mujeres y visibilidad. Alicante, Centro de Estudios de la Mujer, Universidad de Alicante.
} 
y el de la diferencia ${ }^{3}$. Los puntos de partida y de llegada a los que han conducido estas dos corrientes teóricas nos llevan a preguntas radicales: ¿qué es ser feminista?, ¿qué es el feminismo y qué se pretende cuando decimos que nos adscribimos a tal denominación? ${ }^{4}$

Entendemos que el feminismo es un movimiento teórico y político que pretende conseguir la igualdad real entre hombres y mujeres, más allá de las diferencias de las que la biología nos otorga. Es decir, es un movimiento de lucha contra la adscripción de roles y por tanto, de lucha por eliminar las expectativas diferenciales de comportamiento que se basan en factores que no son controlables por el ser humano, puesto que creemos que el tener ciertos caracteres sexuales no debería ser un criterio sobre el cual construir la desigualdad social o, para ser más exactos, una de las manifestaciones de la misma.

La teoría feminista es, ante todo, una teoría crítica de la sociedad, una teoría que irracionaliza la visión establecida de la realidad. El fin de toda teoría es posibilitar una nueva visión, una nueva interpretación del mundo, su resignificación. La teoría, pues, nos permite ver cosas que sin ella no vemos. Por ello, el acceso al feminismo supone la adquisición de una nueva red conceptual, “unas gafas” que nos muestran lo que de otra manera no veríamos.

La teoría feminista indaga en las fuentes religiosas, filosóficas, científicas, históricas, antropológicas, en el llamado sentido común, etc., para desarticular las falsedades, prejuicios y contradicciones que legitiman la dominación sexual. El excelente trabajo de revisión teórica realizado por el profesor Manuel Carlos Silva, "Desigualdades de género: esbozo por un mapa proteórico", que tras realizar una revisión de los principales paradigmas teóricos que han servido para explicar las

\footnotetext{
${ }^{3}$ Una buena exposición de la trayectoria y los conceptos fundamentales que subyacen a estas aproximaciones la podemos encontrar en BELTRÁN, E. Y MAQUIEIRA, V. (eds.) (2001): Feminismos: Debates teóricos contemporáneos. Madrid, Alianza Editorial.

${ }^{4}$ Nos adherimos en este tema a la postura desarrollada por Celia Amorós, defensora del feminismo de la igualdad y que ha sabido ver bien las consecuencias que de este debate se pueden derivar. AMORÓS, C. (2005): La gran diferencia y sus pequeñas consecuencias... para las mujeres. Madrid, Cátedra.
} 
desigualdades de género propone la articulación de los conceptos de género y clase decantándose por la convergencia del modelo marxista con el feminista, así como la necesaria utilización de la visión weberiana, complementada a su vez con el interaccionismo simbólico para lograr la deconstrucción de las legitimaciones y los mecanismos que mantienen a las mujeres en una situación de desigualdad -que recorre los niveles micro y macrosociales-, es un buen ejemplo de cómo abordar esta cuestión. Del mismo modo el trabajo de María Donapetry, "Estado, Iglesia y violencia de género”, examina algunos factores que inciden en el problema de la violencia contra las mujeres, particularmente el concepto de ciudadanía en relación al Estado y la visión que la Iglesia Católica tiene de la mujer como miembro de una comunidad espiritual y social. Se cuestiona la pretendida neutralidad u objetividad del uso que hacen ambas instituciones de términos como "género", “ciudadanía” o "virtud” en el contexto de la violencia contra las mujeres y utilizando la metáfora del panóptico, que le sirve para ilustrar el modo en el que ambas instancias han controlado el comportamiento femenino e influido en su indefensión frente a la violencia, nos advierte del peligro que podría suponer para el feminismo adoptar una nueva visión totalizadora para acabar con ella.

El fin que persigue la teoría feminista es lograr una liberación cognitiva, que implica, en primer lugar, la definición de una situación como problemática; en segundo lugar, la identificación de sus causas y por fin el establecimiento de propuestas alternativas. La puesta en tela de juicio de principios, valores y actitudes aprendidos e interiorizados desde la infancia, y, por supuesto, el paso a la acción, tanto individual como colectiva. El triunfo del feminismo requiere conjugar ambos tipos de acción para poner fin a la doble reproducción del sistema patriarcal, dentro y fuera de las personas, en el espacio público y en el privado, para romper la implacable dinámica de refuerzo mutuo que se da entre las prácticas de la vida cotidiana y las macroestructuras económicas, políticas e ideológicas. Los trabajos de Evija Caune, "Writing Feminity: The case of Anastasia”, y el de Emilia Moreno Sánchez, "Análisis de la violencia hacia las niñas: un estudio de casos en un colegio de primaria”, versan sobre las diferentes maneras en las que se mantienen y reproducen los estereotipos de género, los 
status y roles asociados a la variable sexo (ser mujer, ser madre y esposa ), a través de las construcciones simbólicas que se transmiten en los procesos de socialización mediante la acción de agentes como los medios de comunicación o el sistema educativo. Vivimos en sociedades concretas, históricamente construidas y reconstruidas, con sus mecanismos de producción, reproducción y cambio (cuestión esta última esencial y diferencial con respecto a las sociedades animales). La igualdad entre hombres y mujeres supone participar en dichos procesos, en igualdad de oportunidades. No negamos la existencia de las desigualdades sociales en general,- lo que es una cuestión que tiene que ver con la finitud de los recursos-, pero sí pretendemos participar en igualdad de condiciones en esa arena política. La modificación de la legislación en torno a los derechos de las mujeres es un hito en la consecución de la desigualdad, aunque como muestra el trabajo de Alba Nidia Triana Ramírez, "Violencia contra la mujer en el plano jurídico internacional y colombiano”, el de Isabel Dias, "Violencia e género em Portugal: abordagem e intervençao", y el de Duncan Wheeler, “Intimate Partner Violence in Spain (1975-2006)" para el caso español, no siempre los efectos buscados se consiguen automáticamente, pues hay que tener en cuenta que la influencia que poseen los diferentes discursos (legales, sociales y culturales) es el resultado de una interrelación que a veces nos conduce a "consecuencias no deseadas".

Mientras revisaba las novedades editoriales para introducir este volumen, encontré un artículo de Alessandra Bocchetti, titulado "Lo que no quiere una mujer", dentro de una obra genérica que recogía los textos surgidos como resultado de la realización en Barcelona de un Simposio Internacional sobre las violencias de género en el año $2006^{5}$. Del trabajo de la filósofa italiana me llamó la atención el hecho de que para ella, hablar de la violencia contra las mujeres era participar en "un rito colectivo, secreto y perverso, que aun cuando no sea la intención de nadie en particular, subyace a este tipo de trabajo, a saber, construir la identidad de la mujer sobre la identidad de la

${ }^{5}$ BOCCHETTI, A. (2007): “Lo que no quiere una mujer”, en M.D. MOLAS FONT (ed.), Violencia deliberada: Las raíces de la violencia patriarcal. Barcelona, Icaria. 
víctima”. Por esta razón dice no encontrarse a gusto participando en semejantes debates y acaba proponiendo "convencer a las mujeres para que renuncien a esa falsa identidad de debilidad y miseria (...) a la inocencia del ser víctima (...) porque la verdad es que ciertamente un hombre tiene la culpa cuando maltrata a una mujer, pero hoy también tiene la culpa la mujer que se deja maltratar. Tienen la culpa los hombres que apartan a las mujeres, pero hoy, tienen la culpa las mujeres que se dejan apartar. $\mathrm{Y}$ a mis ojos esta es la culpa más grande” (2007:240).

El malestar que me produjo encontrarme con semejante aseveración me ha movido a reflexionar sobre la cuestión anteriormente aludida: ¿Cómo es posible llegar desde el feminismo, desde cualquier enfoque feminista, a una coincidencia tan grande con el discurso patriarcal? Y yo creo que la respuesta es clara: el feminismo de la diferencia, en su intento desesperado por crear un discurso simbólico propio desde el punto de partida de las diferencias esenciales entre hombres y mujeres, acaba por hacer propuestas no emancipadoras y que sólo aparentemente conducen a lo que ellas denominan insubordinación.

¿Cómo conseguir la igualdad si no es denunciando la opresión? El punto de partida de la reflexión sobre las mujeres tiene que ser, desde mi punto de vista, las vidas vividas dentro de las estructuras concretas de dominación, socialmente construidas y reconstruidas por los actores sociales implicados. Nuestra mirada debe dirigirse por tanto hacia lo socialmente construido, que es desde donde se generan nuestras identidades y no hacia lo naturalmente dado, puesto que los seres humanos actuamos según los significados atribuidos a los elementos objetivos y no sujetos a la determinación biológica del cuerpo como objeto naturalmente conformado. Los trabajos de María Cruz Estada, “Trato y maltrato: una mirada psicoanalítica”, y el de Amaya Ortiz de Zárate, "El deseo sexual, la fantasía narcisista y la violencia”, dan buena cuenta (en ambos casos desde la perspectiva psicoanalítica) de las implicaciones simbólicas que la violencia tiene en la construcción de la identidad de las mujeres para así, y desde ellas, proponer soluciones emancipatorias. 
Intentar elaborar un nuevo discurso simbólico específico de las mujeres basándose en sus diferencias sería tanto como negar nuestra propia historia y con ello, la elaboración de nuestra propia identidad como seres simbólicos. Aunque a lo largo de los tiempos se ha intentado mantener a las mujeres en lugares subordinados, y aún siendo cierto que se ha intentado construir nuestra identidad como "lo otro", tomando como patrón de medida positiva el modelo masculino, no es menos cierto que ésa es parte de nuestra historia y que muchas mujeres se han rebelado frente a tal encasillamiento. Nuestra historia es la historia de la humanidad, la historia de la lucha por conseguir la igualdad en todas sus facetas y la de los intentos de los que mantienen el poder para conseguir que la situación permanezca inalterada e inalterable. En nuestra identidad social está incorporada esa trayectoria recorrida. Las injusticias también forman parte de la historia de las mujeres y, por ende, de la historia colectiva. Desde los albores de la humanidad, las mujeres han sido consideradas como botín de guerra por los ejércitos invasores. El que los hombres de las tribus primitivas violaran libremente a las mujeres de otras tribus no se consideraba punible. ${ }^{6}$ Algunos ejemplos son ilustrativos. En la época de las Cruzadas, los ejércitos que marchaban bajo la Cruz violaban a mujeres del bando contrario en nombre de la religión. En el siglo XV, los conquistadores españoles violaron y raptaron a miles de mujeres indígenas a lo largo de todo el continente, y en el siglo XVIII, los soldados ingleses hicieron lo mismo con las mujeres escocesas. A través del tiempo, las leyes referidas a la violación jamás se liberaron del concepto inicial: que la violación era en primer lugar y sobre todo, una violación de los derechos de posesión del hombre, basados en las exigencias masculinas de virginidad, castidad y consentimiento al acceso privado, como contribución femenina al contrato matrimonial. En el lapso transcurrido desde la II Guerra Mundial hasta los últimos conflictos armados, el mundo ha visto surgir un fuerte movimiento feminista internacional con capacidad de movilización que persistentemente sigue denunciando los horrores vividos por miles de mujeres en las últimas guerras, exigiendo que se tipifique la violación

${ }^{6}$ BROWNMILLER, S. (1981): Contra nuestra voluntad: hombres, mujeres y violación. Barcelona, Planeta. 
sexual como crimen de guerra, una demanda ganada en 1998 al ser incluida dentro del estatuto del Tribunal Penal Internacional. Javier Maravall Yáguez en "Mujeres en movimiento: las prisioneras políticas bajo la dictadura militar chilena (1973-1990)”, analiza desde una perspectiva histórica feminista y centrándose en los 4000 testimonios de mujeres supervivientes recogidos en el informe Valech, el impacto que tuvo la represión de la dictadura militar de Pinochet Ugarte en las mujeres que militaron en la oposición política y cómo se utilizó la tortura sexual como un arma de guerra. Con ello se nos pone de manifiesto la dimensión política de la violencia contra las mujeres, y nos desvela la importancia que toma la destrucción de la identidad femenina (como mujer, madre y esposa) como apropiación de los recursos de los otros, en este caso, los enemigos.

Otra dimensión de la desigualdad, que puede devenir en violencia y maltrato, en este caso institucional, es la que se produce en el ámbito sanitario cuando se objetiviza el cuerpo de las mujeres, sobre todo cuando van a ser madres y que a través del uso de los relatos biográficos focalizados describe el trabajo de $\mathbf{M}^{\mathrm{a}}$ Jesús Montes Muñoz, “¿Por qué no me dejaron? Experiencias de las mujeres en sus partos”.

Es imposible construirse desde la naturaleza, puesto que el ser humano en estado natural no es más que una ficción. No hay sociedad humana sin cultura, ni podemos hablar de seres humanos fuera de la sociedad. Y lo que nos hace humanos es la capacidad de expresar ideas, de situarnos frente a lo dado desde un punto de vista problemático; el ser humano es el único que puede por ello inclinarse hacia el bien y también hacia el mal. La capacidad de juzgar sobre esos conceptos nos separa de la naturaleza y nos separa a todos: hombres y mujeres, pues tanto unos como otros tenemos esa capacidad simbólica que es el lenguaje.

Para Bocchetti, parece que la denuncia de la violencia es la utilización del victimismo como estrategia. Es decir, las mujeres deberíamos pasar a la acción política, mostrando las supuestas virtudes que nuestro ser femenino, nuestra esencia de mujeres, nos otorga y olvidarnos de dar lástima, puesto que para ella, ésa también es una forma de violencia: la violencia de los débiles. Es decir, según esta representante emblemática 
del feminismo de la diferencia, la denuncia de la violencia contra las mujeres no es sino una estrategia débil en política. Creo que en el trasfondo de su discurso hay una aceptación no quiero decir deliberada, pero sí quizá inconsciente, del poder masculino. Para que éste pueda ser ejercido, y dado que se hace de persona a persona, en el seno de los grupos, instituciones y organizaciones sociales, se necesita una justificación ideológica.

Una parte de esa justificación patriarcal descansa en la creencia de que las mujeres también poseemos un poder que se ejerce dentro del ámbito doméstico y que actuaría como contrapeso a sus excesos (la tan manida asunción de que las mujeres “mandan” en casa). Es decir, puede que en sus interacciones los hombres cometan injusticias contra las mujeres, pero lo hacen para contrarrestar el poder que éstas ejercen en el terreno de las relaciones "cara a cara". Justo es, por lo tanto, que un hombre reaccione frente a quien se cree que posee la capacidad de mantener, producir y reproducir la propia existencia y la de la especie. Por tanto, según Bocchetti, más que denunciar los abusos, mejor que hacerse las víctimas, las mujeres debemos exhibir el poder que tenemos para hacernos sujetos de política, o sea, para ser aceptadas como miembros de la polis. Olvida, desde mi punto de vista, que el propio hecho de tener que ser aceptadas como miembros de derecho en la arena política evidencia una injusticia, una falta de poder que debe ser nuestro punto de partida: la exclusión deliberada de las mujeres, por parte de un grupo dominante (los hombres).

Para ella, luchar contra la violencia de género pasaría por hacer ver las grandezas que como mujeres hemos construido. Pero olvida que esas grandezas se han conseguido a pesar de las estrategias de cierre y exclusión social que los hombres han practicado a lo largo de la historia sobre las mujeres. Y olvida además, que esas estrategias siguen vigentes. Que no basta con exhibir los "grandes logros" acerca de la igualdad, sino que hay que denunciar que estos se han conseguido con la oposición activa de unos miembros de la sociedad con respecto a otros. A ese proceso de visibilización de la violencia contra las mujeres han contribuido de manera decisiva los medios de comunicación. De cómo se está haciendo y de las diferentes maneras de 
nombrar un mismo problema social, así como de las consecuencias positivas o negativas que se derivan de ello, se ocupan los trabajos de Diana Fernández Romero, "De parricidio a violencia machista: apuntes para una reflexión sobre la representación de los malos tratos en once años de información periodística”, y el de María Pilar Rodríguez, "Tratamiento de la violencia de género en la prensa vasca".

No deben entremezclarse los conceptos de igualdad objetiva (el hecho de que pertenecemos a la misma especie y que nuestra naturaleza humana -sin hacer referencia al sexo- es esencialmente social, cooperativa y creativa), la diferencia objetiva (la manifestación de caracteres sexuales distintos), la igualdad formal (el ideal de que a pesar de las diferencias sexuales o fenotípicas, todos los seres humanos seamos iguales ante la ley) y la igualdad real (la consecución de ese ideal formal a pesar de las diferencias).

Hombres y mujeres tenemos las mismas capacidades, como miembros de una misma especie, dotada de una capacidad simbólica que nos permite trascender el reino de la naturaleza y satisfacer nuestras necesidades a través de la creación de elementos culturales. El sufragio universal (no tan extendido universalmente como creemos) es la constatación de que la reflexión acerca de cualquier asunto relacionado con la política es no sólo un derecho sino un deber de toda la ciudadanía. Reflexionar sobre un hecho social, como lo es el número de mujeres que año tras año mueren a manos de hombres con los que mantienen relaciones afectivas en todas las sociedades conocidas, debería ser no sólo un derecho sino un deber. Y del mismo modo que a nadie se le ocurriría plantear el silencio acerca del número de robos que se están cometiendo, por entender que tal postura indica una presentación frente a la sociedad de los que han sido atracados como víctimas, no lo debe ser tampoco en el caso que nos ocupa.

"No te hagas la víctima", que parece ser el mensaje de Bocchetti, suena más a imposición patriarcal que a verdadera posición de poder. Sí, somos víctimas y víctimas injustamente tratadas, una vez más silenciadas, incluso por aquellas mujeres que nos quieren ayudar. Tomar la palabra para llamar a las cosas por su nombre significa tener un poder de definir la realidad y como tal, de crear las circunstancias en las que otras 
mujeres tendrán que vivir. No basta con ocupar posiciones estructuralmente reservadas a los varones en virtud de una diferencia que deviene en desigualdad; porque tan importantes como las estructuras son los elementos simbólicos sobre los que éstas se configuran (normas, valores, ideas, creencias, símbolos). Si seguimos creyendo en esencias diferentes, en mundos diferentes, en maneras de hacer diferentes, el resultado serán profecías que se autocumplen y la pretendida "compresencia” no será más que un desideratum.

Durante muchos años, las imágenes y los discursos de las mujeres maltratadas han sido escondidos. Protesta Bocchetti por la exposición que se organizó por el Instituto de la Mujer y que muestra rostros de famosas maquilladas como si hubieran sido maltratadas, porque según ella, el mensaje que se transmite es "ninguna mujer está exenta de que le llegue a ocurrir" y en efecto, el factor de riesgo más importante para ser víctima de maltrato es ese simple hecho: ser mujer. No importa de qué clase social, nivel económico o educativo. Lo sabemos y lo decimos: mujeres de todos los grupos sociales son víctimas de la violencia que ejercen algunos hombres ligadas a ellas por lazos afectivo-parentales por el mero hecho de serlo. Belén Castañón del Pozo, desde su experiencia clínica en una asociación de ayuda a mujeres maltratadas, reflexiona en su trabajo, "Intervención contra la violencia machista desde una perspectiva feminista: mujer y terapeuta”, sobre las diferentes estrategias de actuación con este colectivo.

Se pega o se insulta a una mujer, cuando se cree que esta conducta es legítima, es decir, cuando se ha interiorizado un patrón de desigualdad basado en la diferencia. Son relaciones desiguales (socialmente construidas) entre iguales (biológicamente dotados del rasgo esencialmente humano que es la capacidad de razonar). Relaciones socialmente construidas, sobre la base de diferencias biológicas que no afectan al componente esencialmente humano: ser mujer no merma ni la sociabilidad ni la cooperación ni la creatividad. Y por eso exponemos rostros genéricos, por eso contamos historias, por eso cuantificamos el número de víctimas. Por eso, en definitiva, utilizamos el método científico, para explicar y comprender un comportamiento que aparece con tal regularidad que no puede resolverse con explicaciones que provengan de 
otros ámbitos (biológicos o psicológicos), puesto que como hecho social que es, sólo puede ser explicado a través de otro hecho social. Detrás de un acto de violencia de género están unas maneras de obrar, de pensar y de sentir, externas a los individuos que las protagonizan y que tienen un poder coercitivo en virtud del cual se nos imponen. Que ya existían antes de que esos individuos concretos aparecieran en escena y que nos trascenderán si no las modificamos.

Esas conductas pueden ser explicadas como acciones sociales con arreglo a fines, a valores, afectivas o tradicionales y por eso también intentamos comprender el significado subjetivo de esos comportamientos, que tienen su base en construcciones colectivas y que mediante la comprensión empática causalmente justificada nos pueden mostrar su significado.

Detrás del maltrato a las mujeres existe una desigual distribución de los recursos (económicos, de status y de poder) y también por eso ponemos de manifiesto quién ejerce el poder sobre quién, qué grupos están en conflicto y formulamos la pregunta esencial para cualquier paradigma teórico del conflicto: ¿a quién beneficia este estado de la cuestión?

Incluso dentro de la más rancia tradición funcionalista, la permanencia, la recurrencia y la universalidad de este comportamiento nos haría al menos preguntarnos qué función cumple de cara al mantenimiento del orden social

Por todo eso, señora Bocchetti, y aún compartiendo en buena medida los fines que perseguimos desde la perspectiva feminista general, hacemos hincapié en los puntos de partida divergentes (la consecución de la igualdad en todos los órdenes y no el énfasis en la diferencia desde un punto de vista esencialista) y no nos podemos contentar con "hablar a nuestras hijas con entusiasmo" para recrear un mundo propio creado "ex novo" y a nuestra medida, pues no sería más que una nueva estrategia de ocultamiento e invisibilidad que nos hace aún más víctimas de lo que somos: porque nos haría víctimas de nuestra propia complicidad. Por eso, hoy presentamos un nuevo monográfico sobre la violencia contra las mujeres y sus variadas dimensiones. 
